\title{
Application of Different Strains of Biofertilizers for Raising Quality Forest Nursery
}

\author{
Malik Asif $^{1 *}$, A. H. Mughal ${ }^{1}$, R. Bisma ${ }^{1}$, Zaffar Mehdi ${ }^{1}$, S. Saima ${ }^{1}$, Misbah Ajaz ${ }^{1}$, \\ M. A. Malik ${ }^{1}$, Amjad Masood ${ }^{2}$ and Showkat Sidique ${ }^{3}$ \\ ${ }^{1}$ Division of Basic Sci. \& Humanities, FOA, Wadura, SKUAST-Kashmir, India \\ ${ }^{2}$ Division of Agronomy, FOA, Wadura, SKUAST-Kashmir, India \\ ${ }^{3}$ Division of Agriculture statistics, FOA, Wadura, SKAUST-Kashmir, India \\ *Corresponding author
}

\begin{tabular}{|l|}
\hline K e y w o r d s \\
Biofertilizer, nutrients, \\
$\begin{array}{l}\text { Seedling } \\
\text { improvement, Forest, } \\
\text { Nursery, Quality }\end{array}$ \\
\hline Article Info \\
\hline $\begin{array}{l}\text { Accepted: } \\
\text { 20 September } 2018 \\
\text { Available Online: } \\
\text { 10 October } 2018\end{array}$ \\
\hline
\end{tabular}

A B S T R A C T

Bio-fertilizer is a substance used to increase the fertility of the soil. It contains microorganisms which helps the soil to gain its nutrient back and make the soil available for cultivation. Bio-fertilizer doesn't make any kind of pollution, so it is not a threat to use them in the place of the chemical fertilizers which causes a lot of pollution to the environment. Current soil management strategies are mainly dependent on inorganic chemical-based fertilizers, which caused a serious threat to human health and environment. The exploitation of beneficial microbes as a biofertilizer has become of paramount importance in forestry and agriculture sector for their potential role in healthy growing stock, food safety and sustainable crop production. The application of microbial inoculants (biofertilizers) is a promising technology for future forest nursery raisings and sustainable farming systems in view of rapidly decreasing phosphorus stocks and the need to more efficiently use available nitrogen $(\mathrm{N})$. Various microbial taxa are currently used as biofertilizers, based on their capacity to access nutrients from fertilizers and soil stocks, to fix atmospheric nitrogen, to improve water uptake or to act as biocontrol agents. Plant nutrients are essential for the production of crops and healthy food for the world's ever increasing population. Bio-fertilizer can be an important component of integrated nutrients management in forest ecosystems. Microorganisms that are commonly used as biofertilizer components include; nitrogen fixers (N-fixer), potassium and phosphorus solubilizers, growth promoting rhizobacteria (PGPRs), endo and ectomycorrhizal fungi, cyanobacteria and other useful microscopic organisms. The use of bio-fertilizers leads to improved nutrient and water uptake, plant growth and plant tolerance to abiotic and biotic factors. These potential biological fertilizers would play a key role in production of quality seedlings and sustainability of soil and also in protecting the environment as eco-friendly and cost effective inputs for the farmers.

\section{Introduction}

Biofertilizers are defined as preparations containing living cells or latent cells of efficient strains of microorganisms that help crop plants' uptake of nutrients by their interactions in the rhizosphere when applied through seed or soil. They accelerate certain 
microbial processes in the soil which augment the extent of availability of nutrients in a form easily assimilated by plants. The increasing pressure of human and livestock population, indiscriminate extraction of forest produce, regular forest fires and mining activities have resulted in soil erosion, loss of fertility and moisture content and decreasing productivity of forests which pose manifold problems to restore the ecosystem. Thus, microbial inoculants present in the soil form a strong and important component of our soils, mainly owing to their role to promote plant growth by providing access to the nutrients, nitrogen fixation, mobilization of some unavailable nutrients and production of antifungal antibiotics. The indiscriminate use of inorganic fertilizers and pesticides is neither environmentally safe nor economically feasible. There is pressing demand for microbial inoculants for quality seedling production in nursery and also the establishment of plantation to increase the forest productivity. Bioinoculants are cost effective, ecofriendly, cheaper and renewable sources of plant nutrients and play a vital role in maintaining long-term soil fertility and sustainability. Moreover, they form an important component of organic farming practices. Thus, to meet the challenges like poor regeneration, deforestation and spread of wastelands, introduction of microbial inoculants at the nursery stage of forest trees has become inevitable. Although various aspects of mycorrhizal impact of the forest trees have been studied. In tropical countries like India, there is a problem of nitrogen deficiency and phosphorous non-availability especially in degraded or stressed soils. In order to overcome these deficiencies, chemical fertilizers are being used. However, indiscriminate use of chemical fertilizers regardless of climatic, soil and other factors has affected the environmental quality and soil ecosystem. There are many reports that show adverse effects of inorganic fertilizers on both beneficial micro flora and micro fauna as well as their activities (Zargar et al., 1999). Like other soils forest soils are also facing acute shortage of essential nutrients mainly due to continuous erosion. Moreover fertilization of forest soils is not easy as forests occupy remote, less accessible and less fertile lands. It is therefore feasible to make use of native microbial inoculants as natural nutrient mobilizers for better growth, development and survival of tree species as a substitute for inorganic fertilizers. Simultaneously, the use of microbial inoculants will reduce the use of synthetic fertilizers which in turn decreases the cost of cultivation and ill effects on human health and soil ecosystem, besides improving the growth of plants significantly. Thus, establishment of suitable microbial inoculants is essential to improve the survival and quality of planting stock so as to undertake national developmental programmes of afforestation, reforestation, wasteland-reclamation and social forestry successfully. The present study reviews the impact of various microbial inoculants on plant growth, chemical and microbiological characteristics of forest soils.

\section{Effect of microbial inoculants on plant growth characteristics}

Micro-organisms constitute an integral and significant constituent of soil. There is a vast array of microorganisms in the soil which play their role in improving the soil health as well as plant growth. However, a few microorganisms that play a highly significant role are discussed hereunder:

\section{Effect of Azotobacter and Azospirillum sp.}

Azotobacter was first isolated and described by Beijernick. Related to Azotobacter are other species known as Beiferinckiaindica and Derxiagummosa. In general, Azotobacteris gramnegative, polymorphid, rod-shaped, varying from 2.0 to $7.0 \times 1.0$ to $2.5 \mu$. 
Occasionally an adult cell may measure 10-12 $\mu$, however, the morphology of cells is dependent upon the composition of the medium, species, strains, age of culture and growth conditions; the young cells have Peritrichous flagella which serve as locomotory organs. The beneficial effects of Azotobacter and Azospirillum in terms of improved growth characteristics of various crops is attributed to their nitrogen fixing ability, synthesis of growth promoting substances like indoleacetetic acid, gibberellic acid, Vitamin B and antibiotics, besides enhancement in branching of roots and uptake of $\mathrm{No}_{3}^{-}, \mathrm{NH}_{4}^{+}, \mathrm{H}_{2} \mathrm{PO}_{4}^{-}, \mathrm{K}^{+}, \mathrm{Rb}^{++}$and $\mathrm{Fe}^{++}$ (Ahlawat et al., 1995). Moreover these species have also been reported to inhibit the hatching of egg masses of nematodes, thereby improved the plant growth (Chahal and Chahal, 1988). Microbial inoculants colonize the rhizosphere and stimulate plant growth by providing necessary nutrients, thus enhance plant growth by providing plant growth promoting substances and increasing the nutrient availability in the root zone (Jackobsen et al., 1994).

\section{Effect of Pseudomonas fluorescensand Bacillus subtillis}

Among the various antagonists of fungal pathogens, Pseudomonas and Bacillus spp. are the most important plant growth promoting rhizobacteria. They offer an environmentally sustainable approach to increase crop production and health. They have been found to cause significant improvement in the plant growth of many plants. PGPR are also associated with production of antibiotics, hormones, siderophors and $\mathrm{HCN}$, as well as with molecular mechanisms, which can stimulate induced systemic resistance in plants. It is interesting to note that these mechanisms do not affect the mycorrhizal fungi with which PGPR are associated (Edwards et al., 1999). Dominghez et al.,
(2011) while studying on the seedlings of Pinushalpensis, inoculated with mycorrhizal fungus Tuber melanosporum and the rhizobacterium Pseudomonas fluorescens CECT 844 under non-limiting greenhouse conditions reported that the inoculations improved the growth and nutrient uptake of the seedlings, although the combination of Pseudomonas fluorescens CECT 844 and T. melanosporum did not generally lead to a significant improvement over the positive effects of a simple inoculation of $T$. melanosporium, however, the addition of $\mathrm{P}$. fluorescens CECT 844 did double the rate of the mycorrhization of $T$. melanosporium.

\section{Effect of Pisolithustinctorius and Laccarialaccata}

Mycorrhizal fungi have received considerable interest from researchers, particularly for the past 40 years or so, when their role as modulators of plant growth began to be universally recognized. It is only more recently that their interactions with other soil organisms have been studied in more detail. In natural ecosystem, hundreds of ectomycorrhizal fungi have reported on a single tree species and approximately 70 per cent higher plants are obligately depend on fungal associates, 12 per cent facultatively dependent and 18 per cent remain typically uninfected (Trappe, 1987). It has been estimated that more then 2100 species of fungi form ectomycorrhizae association with forest trees in North America alone while there are over 5000 species of fungi that can form ectomychorrhizae on about 2000 species of woody plants worldwide (Marx, 1969). Pavan (2011) while working on influence of bioinoculants like AM fungi, Rhizobium, Azotobacter and PSB on growth of nursery seedlings of Albizialebeck reported that mycorrhizal association and resting spore population showed an increasing trend till the age of 180 days and the dual inoculation were 
found to be more effective for both AM colonization and biomass production. It was further reported that mixed inocula might be used more efficiently than single inoculum for field inoculation. Anabela (2008) reported that at 50 days of mycorrhizal induction in Castaneasativa plants, growth was higher for mycorrhizal plants than for non-mycorrhizal ones. It was further observed that length of the major roots was lower in mycorrhizal plants after 40 days and fresh and dry weights were higher in mycorrhizal plants after 30 days.

\section{Types of Biofertilizers}

1. Rhizobium 2. Azotobacter 3. Azospirillum4.Cyanobacteria 5. Azolla 6. Phosphate solubilizing microorganisms (PSM) 7. AM fungi 8. Silicate soubilizing bacteria (SSB) 9. Plant Growth Promoting Rhizobacteria (PGPR)

\section{Rhizobium}

Rhizobium is a soil habitat bacterium, which is able to colonize the legume roots and fixes the atmospheric nitrogen symbiotically. The morphology and physiology of rhizobium will vary from free-living condition to the bacteroid of nodules.

They are the most efficient biofertilizer as per the quantity of nitrogen fixed is concerned. They have seven genera and highly specific to form nodule in legumes, referred as cross inoculation group. Rhizobium inoculant was first made in USA and commercialized by private enterprise in 1930s.

\section{Azotobacter}

Of the several species of Azotobacter, A. chroococcum happens to be the dominant inhabitant in arable soils capable of fixing N2 (2-15 $\mathrm{mg} \mathrm{N} 2$ fixed /g of carbon source) in culture media.
The bacterium produces abundant slime which helps in soil aggregation. The numbers of $A$. chroococcum in Indian soils rarely exceeds $105 / \mathrm{g}$ soil due to lack of organic matter and the presence of antagonistic microorganisms in soil.

\section{Azospirillum}

Azospirillum lipoferum and A. brasilense are primary inhabitants of soil, the rhizosphere and intercellular spaces of root cortex of graminaceous plants. They perform the associative symbiotic relation with the graminaceous plants.

The bacteria of Genus Azospirillum are N2 fixing organisms isolated from the root and above ground parts of a variety of crop plants. They are Gram negative. Apart from nitrogen fixation, growth promoting substance production (IAA), disease resistance and drought tolerance are some of the additional benefits due to Azospirillum inoculation.

\section{Phosphate solubilizing microorganisms (PSM)}

Several soil bacteria and fungi, notably species of Pseudomonas, Bacillus, Penicillium, Aspergillus etc. secrete organic acids and lower the $\mathrm{pH}$ in their vicinity to bring about dissolution of bound phosphates in soil. Increased yields of wheat and potato were demonstrated due to inoculation of peat based cultures of Bacillus polymyxa and Pseudomonas striata. Currently, phosphate solubilizers are manufactured by agricultural universities and some private enterprises and sold to farmers through governmental agencies.

These appear to be no check on either the quality of the inoculants marketed in India or the establishment of the desired organisms in the rhizosphere. 
Fig.1 Cultures of different inoculants

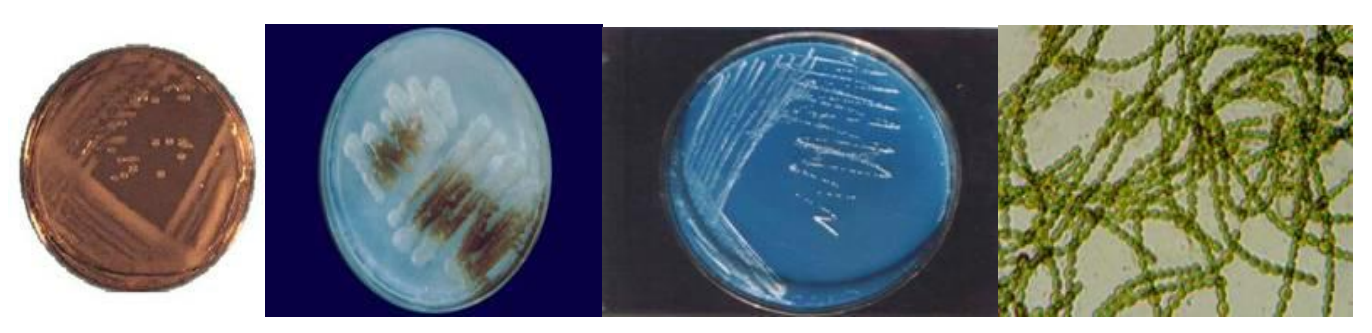

Dosage of liquid Bio-fertilizers in different crops

\begin{tabular}{|l|l|l|l|}
\hline Crop & $\begin{array}{l}\text { Recommended } \\
\text { Bio-fertilizer }\end{array}$ & $\begin{array}{l}\text { Application } \\
\text { method }\end{array}$ & $\begin{array}{l}\text { Quantity to be } \\
\text { used }\end{array}$ \\
\hline Deodar, Cypress \& Blue pine seedlings & $\begin{array}{l}\text { N-Fixers, P- } \\
\text { Solubilizers, } \\
\text { KSB, VAM }\end{array}$ & $\begin{array}{l}\text { seedling / soil } \\
\text { treatment }\end{array}$ & $\begin{array}{l}20 \mathrm{ml} / \mathrm{seedling} \\
1 \text { lit/acre of nursery }\end{array}$ \\
\hline $\begin{array}{l}\text { Agro-Forestry/Fruit Plants All fruit/agro- } \\
\text { forestry (herb, shrubs, annuals and perennial) } \\
\text { plants for fuel wood fodder, fruits, gum, } \\
\text { spice, leaves, flowers, nuts and seeds purpose }\end{array}$ & & $\begin{array}{l}\text { Seedling/Soil } \\
\text { treatment }\end{array}$ & $\begin{array}{l}20 \mathrm{ml} / \mathrm{plant} \mathrm{at} \\
\text { nursery } \\
\text { I lit/acre of nursery }\end{array}$ \\
\hline
\end{tabular}

\section{AM fungi}

The transfer of nutrients mainly phosphorus and also zinc and sulphur from the soil to the cells of the root cortex is mediated by intracellular obligate fungal endosymbionts of the genera Glomus, Gigaspora, Acaulospora, Sclerocysts and Endogone which possess vesicles for storage of nutrients and arbuscles for channeling these nutrients into the root system. By far, the commonest genus appears to be Glomus, which has several species distributed in soil.

\section{Silicate solubilizing bacteria}

Microorganisms are capable of degrading silicates and aluminum silicates. During the metabolism of microbes several organic acids are produced and these have a dual role in silicate weathering. They supply $\mathrm{H}+$ ions to the medium and promote hydrolysis and the organic acids like citric, oxalic acid, Keto acids and hydroxy carbolic acids which from complexes with cations, promote their removal and retention in the medium in a dissolved state.

\section{Plant Growth Promoting Rhizobacteria}

The group of bacteria that colonize roots or rhizosphere soil and beneficial to crops are referred to as plant growth promoting rhizobacteria (PGPR).

The PGPR inoculants currently commercialized that seem to promote growth through at least one mechanism; suppression of plant disease (termed Bioprotectants), improved nutrient acquisition (termed Biofertilizers), or phytohormone production (termed Biostimulants). Species of Pseudomonas and Bacillus can produce as yet not well characterized phytohormones or growth regulators that cause horticulture and forest crops to have greater amounts of fine roots which have the effect of increasing the absorptive surface of plant roots for uptake of water and nutrients. These PGPR are referred to as Biostimulants and the phytohormones 
they produce include indole-acetic acid, cytokinins, gibberellins and inhibitors of ethylene production.

\section{Benefits of liquid biofertilizer technology}

The advantages of Liquid Bio-fertilizer over conventional carrier based Bio-fertilizers are listed below:

Longer shelf life viz; 12-24 months.

No contamination and no loss of properties due to storage upto $45^{\circ} \mathrm{c}$.

Greater potentials to fight with native population.

High populations can be maintained more than 109 cells/ml upto 12 months to 24 months.

Easy identification by typical fermented smell.

Cost saving on carrier material, pulverization, neutralization, sterilization, packing and transport.

Quality control protocols are easy and quick and better survival on seeds and soil.

No need of running Bio-fertilizer production units throughout the year.

Very easy to use by the nursery growers and farmers.

Dosages is 10 time less than carrier based powder Bio-fertilizers.

High commercial revenues and high export potential.

Very high enzymatic activity since contamination is nil.

\section{Methods of applications}

There are three ways of using Liquid Biofertilizers

1. Seed treatment 2. Root dipping 3. Soil application

\section{Seed Treatment}

Seed Treatment is a most common method adopted for all types of inoculants. The seed treatment is effective and economic. For small quantity of seeds (up to $5 \mathrm{kgs}$ quantity) the coating can done in a plastic bags.

\section{Root dipping}

For application of most of the inoculants in forest nurseries this method is used. The required quantity of inoculants has to be mixed with 5-10 litres of water at one corner of the nersery and the roots of seedlings has to be dipped for a minimum of half-an-hour before transplantation.

\section{Soil application}

Use $200 \mathrm{ml}$ of PSM per acre. Mix PSM with 400 to $600 \mathrm{kgs}$ of Cow dung FYM along with $1 / 2$ bag of rock phosphate if available.

The mixture of PSM, cow dung and rock phosphate have to be kept under any tree or under shade for overnight and maintain 50\% moisture.

Use the mixture as soil application in rows or during leveling of soil.

\section{Dosage of liquid Bio-fertilizers in different crops}

Recommended Liquid Bio-fertilizers and its application method, quantity to be used for different forest crops are as follows:

The application of microbial inoculants viz. Pisolithus tinctorius, Laccarialaccata, Azotobacter, Azospirillum, Pseudomonas fluorescencs and Bacillus subtilis is most effective and efficient at nursery stage of most temperate, sub-tropical and tropical forest species. 
Their application improves plant growth characteristics, seedling survival, chemical and microbiological characteristics of the soil.

Environmental stresses are becoming a major problem and productivity is declining at an unprecedented rate.

Our dependence on chemical fertilisers and pesticides has encouraged the thriving of industries that are producing life-threatening chemicals and which are not only hazardous for human consumption but can also disturb the ecological balance.

The new technology developed viz; biofertilizer technology has a wide scope for application in the forest ecosystems.

\section{References}

Ahlawat, V.P., Suneel, S. and Kartar, S. 1995. Plant Microbe Interaction in Sustainable Agriculture. [Eds R.K. Behl, A.L. Khurana and R.C. Dogra]. CCS HAU, Hisar and MMB, New Delhi, pp. 121-131.

Anabela, M. 2008. In vitro mycorrhization of micropropagated plants: studies on Castanea sativa Mill. Sustainable Agriculture and Forestry 10: 319-334.

Chahal, P.P.K. and Chahal, V.P.S. 1988. Biological control of root-knot nematode of brinjal with Azotobacter chroococcum. In: Advances in Plant Nematology [Eds. M.A. Maqbool, A.M. Golden, A.M. Gaffar and A. Krusberg]. Research Centre, University of Karachi, pp. 257-263.
Dominguez, J.A., Martin, A., Anriguez, A. and Albanesi, A. 2011. The combined effects of Pseudomonas fluorescens and Tuber melanosporum on the quality of Pinushalepensis seedlings. Mycorrhiza (10(5): 1007-1016.

Edwards, S.G., Young, J.P.W. and Fitter, A.H. 1999. Interactions between Pseudomonas fluorescens biocontrol agents and Glomusmosseae, an arbuscular mycorrhizal fungus, within the rhizosphere. Microbiology Letters 166: 297-303.

Jackobsen, I., Joiner, E.J. and Larsen, J. 1994. Hyphal phosphorus transport, a keystone to mycorrhizal enhancement of plant growth. In: Impact of AM on Sustainable Agriculture and Natural Ecosystem. [Eds. S. Gianinazzi and H. Schuepp]. Birkhauser Verlag, Switzerland, pp. 133-146.

Marx, D.H. 1969. The influence of ectotrophic mycorrhizal fungi to root pathogenic fungi and soil bacteria. Phytopathology 59: 153163.

Pavan, K.P. 2011. Influence of bioinoculants on the growth of Albizialebeck in nursery conditions. Research Journal of Agricultural Sciences 2(2): 265-268.

Trappe, J.M. 1987. Phylogenetic and ecological aspects of mycotrophy in the angiosperms from an evolutionary standpoint. In: Ecophysiology of VA mycorrhizal Plants. [Ed. S.R. Safir]. CRC Press, Boca Raton, USA, pp. 2-25.

Zargar, M.Y., Dar, G.H., Zargar, A.H. and Ganai, B.A. 1999. Effect of urea on rhizosphere microflora of common bean (Phaseolus vulgaris). SKUAST Journal of Research 1: 52-55.

\section{How to cite this article:}

Malik Asif, A. H. Mughal, R. Bisma, Zaffar Mehdi, S. Saima, Misbah Ajaz, M. A. Malik, Amjad Masood and Showkat Sidique. 2018. Application of Different Strains of Biofertilizers for Raising Quality Forest Nursery. Int.J.Curr.Microbiol.App.Sci. 7(10): 3680-3686. doi: https://doi.org/10.20546/ijcmas.2018.710.425 